\title{
Frontalis muscle flap as sling in severe ptosis
}

\author{
Ramesh C. Nagpal, ${ }^{1}$ Ashima Grover, ${ }^{2}$ Amit Maitreya, ${ }^{1}$ Harsh Baradur ${ }^{1}$ \\ ${ }^{1}$ Department of Ophthalmology, Himalayan Institute of Medical Sciences, \\ Jollygrant, Dehradun, Uttrakhand, India; \\ ${ }^{2}$ Abhilasha Nursing Home, Railway Road, Roorkee, Uttrakhand, India
}

\begin{abstract}
Aim: Evaluation of the effect of frontalis muscle flap as sling surgery in severe ptosis with poor levator palpebral superioris (LPS) action.

Method: Twenty-five eyes of 18 patients with severe congenital ptosis with poor LPS action were studied over a period of two years. It comprised of 13 eyes of 13 patients of severe unilateral congenital ptosis and ten eyes of five patients with ptosis associated with blepharophimosis syndrome. All patients underwent frontalis muscle flap sling surgery and were followed for six months.

Result: At final follow up, $88 \%$ of patients had a satisfactory result. No patients required re-surgery. Lagophthalmos was the most common complication seen which subsided by six months. The surgical lid elevation was effective without any recurrence or complete failure.

Conclusion: Frontalis muscle flap sling surgery is an effective procedure for severe ptosis with poor LPS action.
\end{abstract}

Key words: Frontalis muscle flap, Sling

\section{Introduction}

The treatment of ptosis depends on the degree of ptosis and the individual function of the levator palpebrae superioris, orbicularis oculi and the frontalis muscles. In cases of severe blepharoptosis, however, the levator muscle is essentially non-functional, thus sling procedure, a static correction method, is usually performed. Several surgical techniques have been developed for ptosis correction; however a satisfactory method is yet to be found. ${ }^{1}$

Levator resection in patients with minimal eyelid excursion frequently results in undercorrection. ${ }^{2}$ The frontalis sling with autogenous fascia lata increases morbidity at the donor site with lid lag and lagophthalmos. ${ }^{3}$ Although there are numerous techniques for correction of blepharoptosis, in a severe cases but generally accepted procedure of choice is the frontalis sling which involves different sling materials. The various sling materials have their own inherent shortcomings and complications. ${ }^{4}$

In view of the above, the present study was conducted to see the effect of frontalis muscle flap as sling, which will obviate the need for external sling materials.

Correspondence: Prof R.C. Nagpal, Department of Ophthalmology, Himalayan Institute of Medical Sciences, Jollygrant, Dehradun, 248140, Uttrakhand, India.

E-mail: usharamesh8800@yahoo.co.in 


\section{Materials and methods}

The present randomized, prospective study included a total of 25 eyes of 18 patients who attended the outpatient department of ophthalmology and were diagnosed as severe ptosis with poor LPS action. Written and informed consent were recorded. The inclusion criteria were patients with severe ptosis (marginal reflex distance [MRD] $1<0)$ and poor levator function $(<4 \mathrm{~mm}$ ). Exclusion criteria were mechanical ptosis, dry-eye syndrome, corneal anesthesia, Horner's syndrome, myogenic ptosis (myasthenia gravis), nystagmus, poor or absent Bell's phenomenon, uncorrected vertical squint and previously operated cases for ptosis. A detailed history was taken and clinical examination was carried out.

The desired end result, in unilateral severe ptosis, was measured to be two $\mathrm{mm}$ more than the MRD 1 of the fellow upper lid. While in bilateral cases, the desired end result was two $\mathrm{mm}$ above the limbus.

Procedure: A 12-mm incision made at the eyebrow, lateral to the superior orbital notch, and a 15-mm skin incision was made on the upper lid in accordance to the lid crease of the other eye. A full thickness frontalis muscle flap, to the size of eight to ten $\mathrm{mm}$ in width and approximately ten $\mathrm{mm}$ in length, (variable as per age of the patient), was mobilized by separating it from the subcutaneous tissue above and periosteum below. This flap was brought down to the tarsal plate through a tunnel created below the orbicularis oculi muscle. The frontalis muscle flap was then anchored to the upper one-third part of the tarsal plate with a double armed 6-0 vicryl suture, ensuring its proper level as per pre-op measurements. Both the skin incisions were sutured with interrupted 6-0 silk suture. Eye closed with an inverse frost suture.

All patients of ptosis with blepharophimosis first underwent skin Y-V plasty (Fig. 1) and on the second sitting, frontalis muscle flap surgery was carried out.

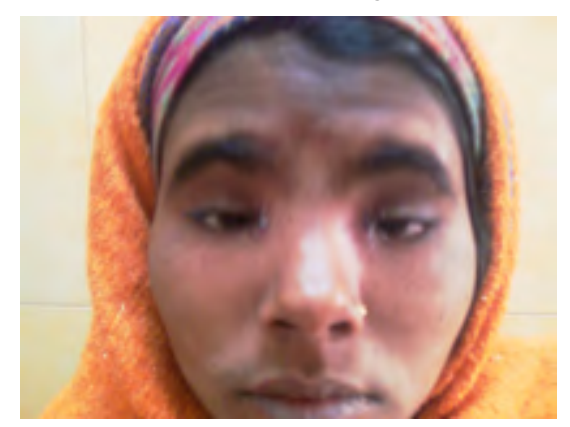

Fig. 1. Blepharophimosis- post VY plasty.

Patients were followed on post-operative day 1, one month and six months. Surgical correction was described in terms of change in MRD 1 from the pre-operative measurements. Pre- and post-operative photographs were taken of all the patients. The data thus obtained were subjected to standard statistical analysis. 


\section{Results}

The study comprised of 25 eyes of 18 patients with male:female ratio 1:1 (nine each). Of the 11 patients of unilateral ptosis $(61.11 \%)$, four were of right eyes and seven of left eyes. Of the seven patients of bilateral ptosis (38.82\%), five patients (ten eyes, 40\%) had an association of blepharophimosis syndrome. Maximum number of patients were in the age range of 7-15 years $(n=9,50 \%)$, there were five patients of less than seven years of age (27.78\%) and four patients of more than 15 years (22.22\%).

Surgical correction was measured in terms of change in MRD 1 from pre-operative to post-operative follow ups on day 1 , one month and six months. The number of eyes having a correction of two to four mm increased from 13 (52\%) to $19(76 \%)$ in six months. Number of eyes with a correction of more than four $\mathrm{mm}$ decreased from $12(48 \%)$ to six (24\%) and five (20\%) on the first post-operative day, one month and six months respectively. Only one eye had a correction of less than two $\mathrm{mm}$ by six months (Fig. 2, Table 1).

Eighty percent of eyes had satisfactory results (MRD 1 within one $\mathrm{mm}$ of the other eye in unilateral cases and palpebral aperture $>$ nine $\mathrm{mm}$ in bilateral cases) whereas $20 \%$ had unsatisfactory results but did not require re-surgery.

Fig. 2.

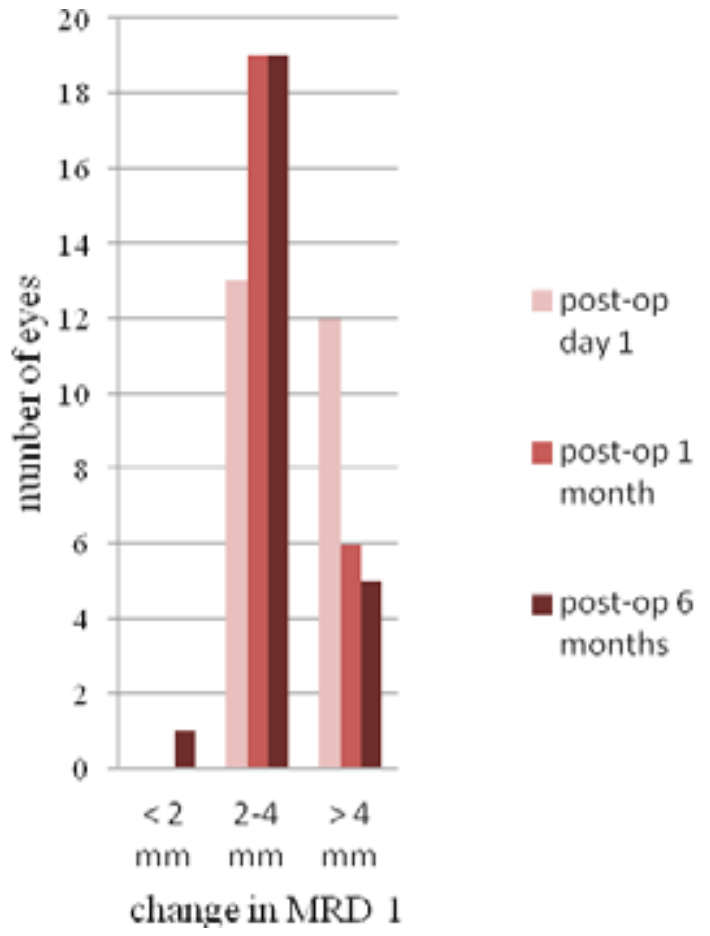


Table 1.

\begin{tabular}{|c|c|c|c|}
\hline \multirow{2}{*}{$\begin{array}{l}\text { Surgical correction } \\
\text { (change in MRD1) }\end{array}$} & \multicolumn{3}{|c|}{ Number of eyes } \\
\hline & $<2 \mathrm{~mm}$ & 2-4 mm & $>4 \mathrm{~mm}$ \\
\hline Day 1 & 0 & $13(52 \%)$ & $12(48 \%)$ \\
\hline 1 month & 0 & $19(76 \%)$ & $6(24 \%)$ \\
\hline 6 months & $1(4 \%)$ & $19(76 \%)$ & $5(20 \%)$ \\
\hline
\end{tabular}

\section{Complications}

The most common post-operative complication was lagophthalmos (100\%) on day 1. Marked lagophthalmos (> one $\mathrm{mm}$ ) was seen in 21 eyes (84\%) while minimal (< one $\mathrm{mm}$ ) was observed in four eyes (16\%). By one month, lagophthalmos resolved in all eyes except six (24\%) which were also free of lagophthalmos by the end of six months. A variable amount of lagophthalmos in different patients disappeared in due course of time due to some amount of drooping of the upper lid over time, and also because these patients were advised exercises for closure of the palpebral fissure. One eye had marked exposure keratitis and resolved with treatment by one month. Hundred percent of eyes had lid-lag in down-gaze which reduced to $40 \%(n=10)$ and $8 \%(n=2)$ by one month and six months respectively. Two eyes (8\%) initially had over-correction which resolved by one month. One eye had post-op entropion which was corrected by revising the sutures. There were no cases of ectropion, lid infection, granulomas, hematoma, loss of sensations, complete failure or relapse.

\section{Discussion}

In the present study, a surgical correction of MRD1 of two $\mathrm{mm}$ or more was seen in $96 \%(n=24)$ at the final follow up, with satisfactory results in $84 \%(n=21)$ and none of the eyes required re-surgery. Similar results (95\%) were obtained by Robert et al. where a correction of MRD 1 equal to or more than two $\mathrm{mm}$ also included cases of re-surgeries. ${ }^{5}$ Ye et al. reported 5\% ptosis relapse and 3\% unnatural contour of the palpebral margin, which were subjected to re-surgery. ${ }^{6}$

Of the ten eyes of five patients with blepharophimosis who underwent bilateral frontalis muscle flap sling surgery in our study, $80 \%(n=8)$ had satisfactory results and none of the eyes required re-surgery (Fig. 3). Results have been found to be similar to that of Betharia ${ }^{7}$ and Islam et al. ${ }^{8}$

Post-operatively, all patients had lagophthalmos and lid lag to begin with, which resolved in $76 \%$ by one month and in $100 \%$ by six months. In similar studies by Black et al. ${ }^{9}$ and Tucker et al., ${ }^{10}$ lagophthalmos persisted in 14\% and 9\% respectively at their final follow up of one month. Similarly, Betharia et al. also reported disappearance of post-operative lagophthalmos in all cases by three months. ${ }^{7}$ Similar 
results have also been reported by Islam et al. with $100 \%$ cases having lagophthalmos post-operatively which improved in all patients over a follow up of 4-18 months. ${ }^{8}$

None of the cases in the present series had post-operative ectropion, though it has been reported by other authors to the tune of 3.5\%. ${ }^{6}$ Absence of postoperative ectropion in our study was probably because of the fact that the muscle was carefully sutured with the tarsal plate at its upper one-third portion without evertion of the lid margin.

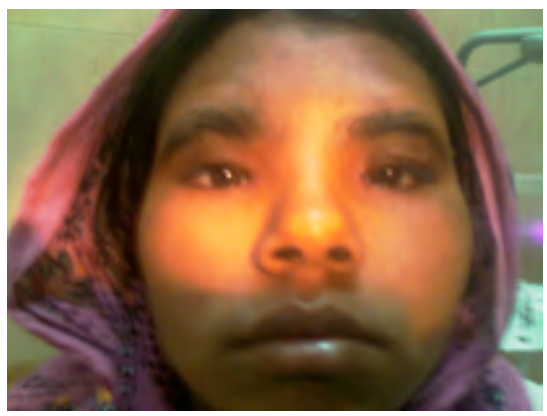

Fig. 3. Post frontalis muscle sling surgery (bilateral).

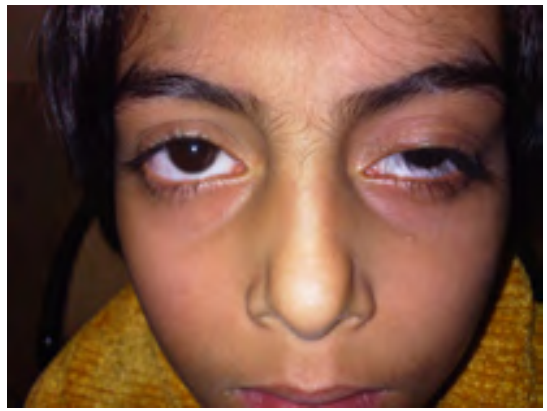

Fig. 5. Left eye severe congenital ptosis- Preoperative.

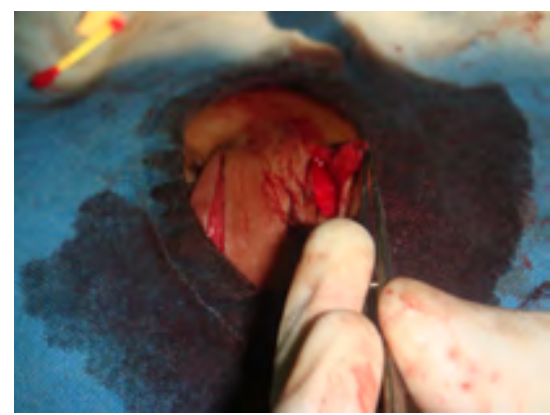

Fig. 4. Fashioned frontalis muscle flap.

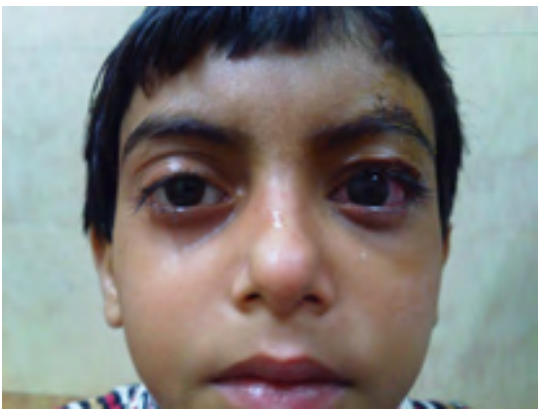

Fig. 6. Left eye frontalis muscle sling surgery - postoperative.

Frontalis muscle flap surgery, in patients of severe congenital ptosis with poor LPS action had satisfactory results in $84 \%$ without subjecting any eye for re-surgery (Fig. 4). Similar results have been repoteted by Betharia et al. ${ }^{7}$ Though lagophthalmos was present in $100 \%$ of the eyes to begin with, it resolved with duration of time within six months. Similar results have also been reported by Black et al. ${ }^{9}$ and Betharia et al., in which lagophthalmos was present in all cases that disappeared by last follow up. The present technique obviated all the post-operative complications of sling materials such as suture granulomas, infection, broken sling, prolonged lid edema, lid retraction, abnormal lid contour and lid crease or broken sling and cheese wiring with relapses. ${ }^{7,10}$ 
Frontalis muscle flap surgery in severe congenital ptosis proved to be an excellent technique, especially in unilateral cases, thus avoiding surgery in the sound eye, as is the case with sling surgeries. (Fig. 5,6) $3,6,7$

\section{Conclusion}

Frontalis muscle flap as sling surgery in our study has proved to be an excellent technique for treatment of unilateral as well as bilateral severe ptosis with poor LPS action, with or without associated blepharophimosis syndrome. Results were excellent in terms of lid elevation with good lid contour, with its final satisfactory functional and cosmetic results. This procedure with its excellent results obviated the need for surgery on the sound eye. Like any sling surgery, this procedure has a major problem of post-operative lagophthalmos and lid lag which needs meticulous care till its resolution.

\section{References}

1. Collin J R O. The Surgical management of Ptosis. Plast Surg 1990; 2(1): 1759.

2. Berke R N. A simplified Blaskovics operation for blepharoptosis. Arch Ophthalmol 1952; 48: 460.

3. Crawford J S. Use of fascia lata in the correction of ptosis. Adv Ophthalmol plast Reconstr Surg $1982 ; 1: 221$.

4. Carraway JH. Reconstruction of the eyelids and correction of ptosis of the eyelid. Plastic surgery. 5th. New York: Lippincot-Raven; 1997: 529-44.

5. Robert CK, Francesco PB, Lucie K, Moin M, Roumeliotis AA and Kulwin DR. Unilateral frontalis sling for correction of unilateral poor function ptosis. Ophthal Plast Reconstr Surg 2005; 21(6):412-7.

6. Ye XN, Yang QH, Chen X, Zhou SJ, Wang KY. Frontalis muscle facial flap passing through the pulley of orbital septum for correction of severe blepharoptosis. Zonghu Zheng Xing Wai Ke Zhi 2007; 23(5): 396-8.

7. Betharia SM. Frontalis sling: a modified simple technique. Br J Ophthalmol 1985; 69: 443-5.

8. Islam, Zafar, Rehman, Habib, Khan and Muhmmad. Frontalis muscle flap advancement for jaw-winking ptosis. Ophthalmol Plast Reconstr Surg 2002; 18(5): 365-9.

9. Black EH, Basse L, Gladstone GJ, Brazzo BJ, Nesi FA et al. Predicting lagophthalmos in ptosis surgery. Invest Ophthalmol Vis Sci 2002:43; abstract 1471.

10. Tucker SM and Cabral H. Incidence of lagophthalmos after aponeurotic ptosis repair. Orbit 2000;19(2):61-66.

11. Ibrahim and Ali $\mathrm{H}$. Use of the Levator muscle as a Frontalis sling. Ophthalmol Plast Reconst Surg 2007; 23(5): 376-80. 